discovery that during the periods of two surveys carried out in April and August 1968, only six visits were made by members of the museum staff to the museum library and reading rooms. The case for absorbing OSTI is also strong-in the brief span of its existence, this organization has been too imitative of what happens elsewhere and too unconcerned with the practical uses made of the scientific literature. If it can be kept from being too uppish in a new organization, it could help to provide the long-term research which the library services need.

It is less sure that the new authority should be as much under the thumb of the Department of Education and Science as the Dainton committee suggests. The Dainton committee comes out for a management board appointed by the Government and organized very much as if it were a nationalized industry. Quite explicitly, the committee says that it does not want to see the management of the libraries left in the hands of trustees as at the British Museum under present arrangements, chiefly because it wants there to be full-time and efficient management. All that is fair. The danger is that direct dependence on the Government will perpetuate the traditions of parsimony which have literally beggared the libraries in the past few years while, at the same time, serving to isolate them still further from the university libraries up and down the country. So is there not at least a case for asking that the new service should be run by a management board appointed by trustees on which the universities and the research councils are strongly represented, or even for asking that funds should come not directly from the Department of Education and Science but from the government agencies responsible for the health of scholarship - the UGC and the research councils ?

On two other points, the Dainton committee is entirely sensible. First, it asks that both the British Museum library (to be renamed the National Reference Library) and the National Reference Library for Science and Technology (which should not be called the Central Science and Patent Collection as Dr Dainton suggests) should be rehoused in central London. Second, it suggests that even though both of these should be independent units within the National Libraries Authority, there would be advantages in having them close together. The most urgent practical need occasioned by the report of the committee is that the Government should find somewhere to build these two institutions, and Covent Garden is an obvious place. The strongest case for having them adjacent to each other is a point the importance of which the committee has underestimated - the need that collections in the history of science should be easily accessible not merely to historians, as at present, but to scientists as well.

What the committee has to say about research and the future development of national libraries is also sensible. Perhaps the greatest need is that arrangements should be made for handling bibliographies by computer. Centralization will obviously help. The ideal is that the new libraries authority should go much further than librarians (and even Dr Dainton's committee) would wish in devising means of compiling bibliographies based on usage as well as formal relevance. In the long run, however, the development of tools for the more efficient use of libraries requires not merely that there should be a more efficient central network within Britain, but also that British practices should be closely married with those of other countries. In this sense, the Dainton committee does less justice than it might have done to an important cause. Is it, for example, sensible to make heavy weather of the problem of storing enough literature in foreign languages when there are obvious opportunities for coordinating national library systems within western Europe ?

The implications of what the Dainton committee has to say about the cost of running the National Libraries Authority will, quite understandably, cause a great deal of anguish. The management board which the committee would like to see would be expected to operate more or less commercially, making hardheaded decisions about the point at which it would be economic to store library material in outlying stores, not central London. By the same test, it would be necessary to decide that some material should be stored on film, not in the flesh. Undoubtedly this will affront a great many users and of course there is always a danger that boards of management given unduly commercial terms of reference will skimp on the convenience of readers. Yet the Dainton committee is right to emphasize that the cost of operating the libraries now in service is alarming. At the National Lending Library for Science and Technology, for example, the total cost works out at $£ 1 \cdot 15$ for each loan of a book or journal. The cost of storing books seems to vary enormously from one site to another, but works out at about $£ 0 \cdot 25$ per volume per year. Given that, in libraries like the British Museum, many volumes are used only once in ten years, the cost for each use works out at $£ 2 \cdot 5$. In circumstances like these, it might have been entirely proper for the committee to have gone the whole hog and to have suggested that many books should be kept but never lent. In the long run, the answer to a great many of the problems with which the Dainton committee has been concerned may be a method of reproduction which is cheap enough to provide a potential borrower or user not with a sight of an original book, but with the gift of a copy of it.

\section{ENRICHED URANIUM Slow Spin for Centrifuges}

THere is plainly some disappointment among the governments of Germany, the Netherlands and the United Kingdom about the progress made in Bonn on June 9 towards a tripartite agrecment on the development of plants for separating fissile uranium 
by the use of gas centrifuges. The communiqué issued after the meeting is heavy with phrases such as "questions of substance still to be decided". What seems to have happened is that the ministers of the three countries-two from each side-were presented with a report on progress so far towards the solution of technical and political problems together with a draft of a treaty. Some points in the documents prepared by the officials have plainly been accepted by the politicians, although the communiqué says that the draft treaty will have to be amended in the light of the discussions at Bonn. Enough progress towards an agreement seems to have been made for the three governments to have agreed that industrial enterprises -including public corporations such as the British fuel manufacturing company-should be brought into the discussions. (From the beginning, the intention has been that industrial companies should be tightly integrated with the plans for making centrifuges.) But there is no longer any of the optimism which allowed people to say, as recently as March, that it might be possible to sign an agreement in principle at the meeting which took place earlier this week.

What lies ahead? Although it has plainly been something of a surprise that the negotiations have turned out to be as tough as Monday showed them to be, cheerfulness is still the order of the day among the negotiators. Most probably it is a combination of technical and political considerations which has made the going unexpectedly difficult, and certainly there will be great rejoicing among those who make and sell fissile materials when eventually it is possible to understand the commercial advantages of the bulk production of uranium-235 by gas centrifuge. Certainly there seems to be no doubt that the intervention of Euratom has been unimportant. Nobody seems to be concerned at the clarion call from Brussels that the use of this technique should be organized on an international basis, preferably within the EEC. This, however, probably explains the statement in the Bonn communiqué that there would be consideration for the participation of other governments once the tripartite enterprise had become a going concern.

\section{DRUG CONSUMPTION \\ Eating More Pills}

PeOPLe seem to have an insatiable appetite for pills, and the richer they are the more they take and the more they are prepared to spend on medicines in general. Doctors seem equally happy to prescribe more medicines. These apparently universal trends, which carry the risk of sickness through excessive use of drugs as well as waste of money, prompted the Swedish Government in the spring of 1964 to suggest that the World Health Organization should make a survey of European drug consumption. The report of a pilot survey in six European countries-Austria, France, Hungary, the Netherlands, Sweden and the United Kingdom-will do nothing to dispel the Swedish Government's alarm.

In all six countries, the increase in drug consumption and its cost is now a cause for anxiety. The WHO consultants say that the amount of information they were able to collect was insufficient to suggest how best to obtain the optimum level of drug consumption or to make strict comparisons of the situation in different countries.

As would be expected, there is considerable variation in the pattern of drug consumption not only between but within the six countries. In general, urban communities consume and spend more on medicaments and medical care than their rural counterparts. The people of Budapest spent 349 florints on medicines in 1965, while the average spending in the rest of Hungary was 200 florints. There are also considerable differences in the amount spent on drugs in the six countries and the types of drugs used for particular diseases.

The rise in cost of prescribed drugs in the past ten years has generally outstripped the increase of national incomes, and is more evident in general practice than in the hospitals. One common cause is the tendency of general practitioners to prescribe proprietary drugs. The clearest example of this trend is in Britain. In 1949 the average cost per ingredient in the 202 million prescriptions was 16.4 pence, but by 1965 the comparable figure had increased to 84.4 pence. And in Sweden, the average cost per prescription rose from $6 \cdot 49$ to $12 \cdot 36$ kroner between 1955 and 1964 . The increasing consumption of proprietary drugs-in Britain in 1964-65 they constituted 75 per cent of all drugs prescribed-is familiar enough. The report notes, for example, that several committees in Britain have commented on the fact that the medical profession, while stoutly defending the right of each doctor to have maximum freedom to prescribe any drug for his patient, too often succumbs to advertising and ends up by prescribing costly proprietary medicines for which there are cheaper alternatives.

Among the six countries surveyed, the number of prescription items per head of the population correlates with the number of doctors per head of the population. There was no correlation between consumption of prescription of over-the-counter drugs with the number of pharmacies. The survey also could find neither evidence that rigid government control of manufacture or marketing of drugs influences total consumption, nor evidence for the assumption that the availability of a large number of drugs affects total consumption. On the other hand, a liberal policy of admitting drugs to the market increases the risk of consumption of less effective drugs. The report also calls for more noncommercial communication about drugs in addition to the ever growing "commercial communication"its euphemism for advertising. This is steadily intensifying in Europe, although it has not yet reached the levels in the United States, where the drug companies spend about $\$ 4,000$ a year per physician.

\section{PHARMACEUTICALS \\ Keeping Watch on Drugs}

IT will be interesting to sec whether the Dunlop Committee becomes known as the Frazer Committee now that Sir Derrick Dunlop has resigned the chairmanship of the British Government's Committee on Safety of Drugs and Dr A. C. Frazer has succeeded him. Certainly that is likely to be the most noticeable change. Sir Derrick, who has been chairman of the committee, which acts as a watchdog for the British Government on the new drugs and formulations put on the market 